\title{
A Case Study on Enneagram Personality Types, Interpersonal Relationships and Job Stress
}

\author{
So-Hyoen Park ${ }^{1}$, Mi-Na Lee ${ }^{2}$ \\ ${ }^{1}$ The Doctor's Course, Department of Human Service Education, Kwangshin University, South Korea, \\ 6770love@hanmail.net \\ ${ }^{2}$ Professor, Welfare Counseling Convergence Department, Kwangshin University, South Korea, \\ lmn4780@naver.com
}

Corresponding author: $\mathrm{Mi}-\mathrm{Na}$ Lee

\begin{abstract}
This is a single case study using adaptive counseling approach on the type of Enneagram and post-employment experience of a client experiencing difficulties in interpersonal relationships and coping with job stress. The research participant was a 26 -year-old young woman working $\mathrm{N}$ city who recognize the type of Enneagram and experience difficulties in interpersonal relationships and job stress. The study was conducted in a total of 20 sessions from December 7, 2020 to April 26, 2021. The research tool used was a K-type Enneagram personality test, interpersonal relationship, and job stress measurement tools. Thus, the research participant was able to understand herself and explore social life and interpersonal relationships through the Enneagram type. This study also examined the effects of positive resource using interpersonal and job stress testing tools before and after the adaptive consultation. Therefore, through adaptive counseling, the subject actively expressed things that she had not experienced before the counseling while proceeding with the process of 'understanding herself, telling about his daily experiences, informing her strengths, social support system, and designing future life'. These experiences provided daily vitality and pleasure and provided insight into self-inspiration and current life by looking at oneself separately from job stress. This study is intended to help client preparing to adapt to their jobs after employment find themselves.
\end{abstract}

Keywords: Client, Enneagram Personality Type, Interpersonal Relationships, Job Stress, Adaptation Counseling

\section{Introduction}

Youth is a time of instability and possibility. The open possibility of various choices and alternative possibilities for young people means that they are unstable and unable to settle down. Young people get to know themselves more deeply by constantly establishing and revising various plans for life and moving toward the future they want[1].

Recently, the economic activity and job market shrinkage due to the COVID-19 pandemic has been growing in the aftermath of unemployment and closure. The number of employed people has been decreasing since March 2019, as well as youth employment due to the continuation of COVID-19. Young people, including ordinary people, are directly and indirectly affected by the employment blind spot. According to the "September Employment Trends" of youth employment, the number of employed plunged nearly 400,000 from the same month last year due to the strengthening of social distancing

Received: June 22, 2021; $1^{\text {st }}$ Review Result: August 07, 2021; ${ }^{\text {nd }}$ Review Result: September 23, 2021 Accepted: October 31, 2021 
caused by the spread of COVID-19. One in four people is unemployed, with the unemployment rate soaring to $13.5 \%$ and the youth unemployment rate soaring to $25.4 \%$, indicating the worst employment situation[2]. As such, the prolonged covid-19 is currently increasing the stress of employment for young people preparing for employment in Korea along with various social factors such as economic recession and youth unemployment.

The future of youth is also a very important factor in the development stage after adulthood. As a result, social interest in youth issues in Korean society is gradually increasing. Youth can be seen as a period of time when an individual's overall lifestyle is formed[3]. Considering this, the transition to the labor market due to high education in Korean society, the idle labor force due to the instability of the labor market, economic dependence on parents, delay in marriage and low birth rate[4] has been gradually delayed. As such, the delay in young people's fulfillment of adulthood can be said to be raising concerns about the psychological and social instability experienced by young people.

Statistics Korea data in June 2020 showed that the number of unemployed was 1.228 million, up 91,000 from a year earlier[5]. This is creating an economically inactive population who do not engage in economic activities because of job preparation despite having labor capabilities in the face of job insecurity. In addition, the economically inactive population of job seekers increased by 541,000 compared to the same month last year, of which the number of job seekers who were unemployed within a year but abandoned their jobs due to labor market conditions increased by 24,000 compared to the previous year[5].

According to the Korean government's plan to improve the lives of young people, young people recognized their difficulties as social and structural problems, not individual problems, and raised the need for government-level support. By accepting the voices of these young people, the youth policy is expanded from job-oriented to youth life, including housing, living, and participation. The need for support throughout youth life is also being raised in the mental health sector, affecting the direction of major mental health projects.

The youth policy strategies presented in the 2020 Mental Health Business Guide[6], includes: first, increasing the use of mental health services by improving awareness; second, early detection and intervention of mental health problems; third, establishment of a mental health support system by life cycle; fourth, early intensive care to prevent chronic disease; fifth, improving the quality of life for people with severe and chronic mental illness; and sixth, strengthening the human rights of mentally ill people. As a result, adaptation to work right after employment in youth is a very important factor. Postemployment adaptation may be affected by the risk of conflict during an individual's development, but may also result in a return to the previous level of adaptation[7]. If you look at prior studies related to adaptation, there is adaptation flexibility. Adaptive flexibility has a significant static effect on career attitudes maturity and career preparation behavior[8], and studies conducted on young people indicated that adaptive flexibility has a significant static effect on job search efficiency[9].

Furthermore, it is important to understand the concepts of 'risk factors' and 'protection factors' that work with adaptability flexibility because adaptation flexibility is different by personal or environmental factors, situations or interactions in context[7]. Confidence and optimism among the subfactors of adaptive flexibility have been shown to play a role in controlling job stress and efficacy[10].

This can be said to be less experienced by developing adaptive flexibility along with efficacy even under job adaptation stress. This can be said to increase job adaptation activities through flexibility to return to before individuals are stressed, although they are stressed out in preparing to find a job after graduating from college. Furthermore, various stressors related to adaptation are highly inextricably related to individual and social factors. In the face of a stress situation, we find the reason for the occurrence, but to return to the previous adaptive situation, coping is more important than solving the cause[11].

Lazarus and Falkman (1984)[12] stated that the type of adaptive stress coping ability is distinguished 
by problem-driven and emotion-oriented coping in the face of the job adaptation stress they are experiencing. In other words, we distinguished it as problem-oriented coping, an effort to change the problematic situation, and emotion-oriented coping, which controls emotions caused by job stress.

Other studies have shown that job seekers strive to challenge and adapt to the changing job market, but experience both employment and job adaptation stress in this process. Stress arising from job hunting can be referred to as employment and adaptation stress, which has a talismanic effect on job preparation behavior[13]. There is also job adaptation stress that experiences difficulties in adapting after employment to improve it. Shim Min-jung (2019)[14] said that employment patterns may vary depending on how to deal with job stress situations. That is, when experiencing high adaptive stressful events, adaptive stress coping methods that select how to handle them play an important role[15].

As such, adaptive stress events experienced in everyday life have been reported through prior studies to relate with physical and psychological adaptation and are known to have more negative effects than positive effects. Furthermore, the negative effects not only result in personal discomfort, but sometimes serious levels of physical and mentally illness, which can result in interpersonal conflict or disruption at a social level.

This study was conducted to examine the interpersonal relationships and job stress experienced by women after employment through the counseling process. The research questions to this end are as follows.

First, how did the subject experience job adaptation after getting a job?

Second, is the type of Enneagram and interpersonal and adaptive stress effective for the subject?

\section{Theoretical Background}

\subsection{The Youth Understanding}

Youth is a life cycle transition from adolescence to adulthood, attracting attention as an independent new stage of development[16].

Youth experiences emotional anxiety, which can be described even in stormy times, but this is a natural phenomenon that occurs during the transition of the developmental stage and can slowly regain emotional stability[17]. This led to discussions on new developments due to the delay in entry into adulthood, and the representative concept is "Emerging Adult" presented by Arnett (2004). Arnett (2004)[18] stated that this is a time of various changes that deviate from childhood and adolescent dependencies, but still do not hold the normative roles and responsibilities of early adulthood and try to acquire new knowledge and skills to successfully move into adulthood[19].

The age standards for youth are defined differently by scholars, and there is no agreed age regulation for youth in Korea. Kim Ki-hun et al. (2010) said that if young people are considered to be social age rather than biological age, there will be no need to refer to a certain age period as young people, because the timing of transition to adults such as employment and marriage varies from person to person. As such, the definition of age groups is explained differently by society, by age, and by policy needs[20].

Looking at the characteristics of Erickson's adolescent phase of psychosocial development[21] first, adolescence has a firm sense of subjectivity Since youth after self-identification is formed, it has flexibility in interpersonal relationships and social life along with the maturity of personality and emotional stability. Second, youth becomes comfortable with interpersonal relationships. The establishment of self-identity enables a healthy relationship with others as an independent adult. Third, youth can have a deep interest in hobbies. Unlike the interests of infancy and adolescence, Youth cares more deeply about their hobbies and spends time, money and energy on them. Fourth, adolescence is a time of marriage. With mature faith and love, one can have true sexual relationship with others without fear and guilt. In addition, through true friendship, they choose their spouse, love each other, and gain 
satisfaction in their lives. Fifth, adolescence has conditions to become a parent. Marriage through engagement can lead to childbirth, family formation, and mental and material responsibility for raising children. Sixth, youth chooses a job. They choose a job based on one's aptitude, income, social status, have satisfaction with the job, and faithfully fulfill one's responsibilities at work[21].

\subsection{Understanding Enneagram}

Enneagram distinguishes human personality into nine systematic and structured types, and is used as a useful tool to help solve human problems and resolve conflicts caused by human relationships. Everyone has one of the nine personality types of Enneagram and remains consistent throughout their lives[22]. However, even if they are of the same personality type, they differ in dynamics. The Enneagram personality types do not exhibit differences by culture, race, gender, religion, or age, and each type has its own characteristics.

Unlike other personality-type tools, Enneagram is a very specific tool that can identify and understand each person's basic core needs and potential, and the causes and motives of speech and action. Enneagram is an elaborate tool that can after accurately "self-awareness" because it comprehensively explains the dynamics of the mind, up to the prototype of the entire human body. Self-exploration, a process of "self-awareness" through Enneagram, can be used to understand oneself multifacetedly, and this self-understanding can be said to be useful if an individual wants to grow. Enneagram is a personality theory based on internal and core motivations for human behavior, interpersonal relationships, emotional aspects, and internal representations, which dynamically shows external lifestyles, diverse activities, and personality attitudes. Enneagram provides an integrated and dynamic understanding of human beings by presenting and emphasizing the direction of basic personality types, wings, divisions, and integration that represent more internalized motivations, habits, and personality changes[23].

Enneagram terms are often translated into different words by translator, somewhat different from those used in psychology, or often have meanings in deeper dimensions. It was intended to explain what the term used in the Enneagram meant by meaning. Beyond the general definition of the term itself, the interpretation and translation of the Enneagram term were to be used separately. For example, passion is translated into passion in the positive sense and passion in the negative sense. Second, perfection is translated completely in the positive sense and perfectly in the negative sense. Third, holy ideas is translated as sacred thinking. Fourth, fixations were translated as stuck.. Fifth, virtues are into virtue. Sixth, spiritual is translated into spirit. Enneagram is a combination of the Greek word Ennea meaning "nine" and the Greek word "gramos" meaning weight, picture or dot. The picture symbolizing Enneagram consists of a circle representing totality, a triangle representing the triangularity of the universe, and a hexad that shows how the totality (circle) and three forces (triangle) interact to achieve the results, and how it continues to change and evolve.

Enneagram consists of circles, triangles and hexad, and three symbols represent the divine law governing everything in existence. First circle refers to unity, and God is one. This is the logic taught by major Western religions such as Judaism Christianity and Islam. Second the triangle means 'the law of three' and everything that exists is the result of the interaction of the three forces. It means the Trinity of the Father, Son, and Holy Spirit of Christianity, and the Buddha and the Law of Buddhism. It stands for "vishnu" "brahma" "shiva" of Hinduism, and means the sky, land, and people of Taoism. In other words, the world's major religions claim trinity. In ancient tradition, people were also divided into three categories: men, women, and children, not men and women, and colors were divided into three categories: black and white as well as gray. Thirdly, hexad shows that everything that exists is not stagnant. Everything moves and changes into something else. Hexad means that everything that exists varies depending on the forces acting on it and its nature, but everything changes, regenerates, and 
evolves[23].

In Enneagram, human personality types are classified into three groups: head-centered (thought-type), chest-centered (emotional-type), and belly-centered (behavioral-type). In other words, a person lives in a world where one center is more dominant than the other two centers. In other words, if you think, feel and act in one central energy, you can maintain your own comfort and do what you want easily. Central energy can control or identify the reactive behavior of a person, especially when they lose composure or are stressed out by internal and external situational factors[22]. Enneagram can be divided into thought, emotion, and behavioral content. The thinking type corresponds to types 5, 6 and 7 of the head type, the emotional type corresponds to types 2,3 and 4 and the behavior type can be divided into types 1,8 , and $9[23]$.

Type 8, Type 9, and Type 1 is called the instinct group.

Type 2, Type 3, and Type 4 is called a group of emotions.

Type 5, Type 6, and Type 7 is divided into three groups of accidents.

This concept of fundamental centrality is rooted in long-standing oriental philosophy, and refers to the daily way we respond to various events in life, especially inner reactions. Type is represented by the combination of the expression style at each center of power and the core internal needs that one has.

The Enneagram classified human personality types into instinctive, sensory, and thinking types. Human personality types are organized by the center of power and the three selves. It represents the main problems and defenses of the ego that reduce self-consciousness and limit itself, and you can see where the imbalance lies. The Enneagram personality types are shown in [Table 1].

[Table 1] Enneagram Personality Types

\begin{tabular}{ccc}
\hline Classification & Type & Contents \\
\hline Instinct center & $8,9,1$ & $\begin{array}{c}\text { You are drawn to your own instinct, the source of your vitality, and your power. } \\
\text { Focuses on the body, basic life functions, and survival based on physical tension } \\
\text { They tend to have problems related to aggression and oppression. } \\
\text { He has a lot of anger behind his self-defense behavior. }\end{array}$ \\
\hline $\begin{array}{c}\text { Emotion } \\
\text { center }\end{array}$ & $2,3,4$ & $\begin{array}{c}\text { Interested in false or disguised self-images } \\
\text { Thinking } \\
\text { center }\end{array}$ \\
\hline $\begin{array}{c}\text { They believe that their stories and characteristics are their real identity. } \\
\text { Self-defense and shameful. }\end{array}$
\end{tabular}

The Hornevian group type, structured in a social way, indicates whether the most overriding needs are being met. [Table 2] shows the Honibian type that explains the social way.

[Table 2] Hornevian Group Type

\begin{tabular}{ccc}
\hline Classification & Type & Contents \\
\hline Assertive Type & $3,7,8$ & $\begin{array}{c}\text { It is ego-centric and seeks to expand the ego. } \\
\text { When faced with difficult situations, they inflate their ego. }\end{array}$ \\
\hline Compliants Type & $1,2,6$ & $\begin{array}{c}\text { I have a desire to serve people. } \\
\text { These are advocates of truth, revolutionaries, volunteers, and hardworking workers. }\end{array}$ \\
\hline Withdrawns Type & $4,5,9$ & They respond to stress by withdrawing from their association with the world and entering \\
their imagined 'inner place'.
\end{tabular}

The Harmonic type reveals the basic way the personality defends itself in the face of loss and disappointment. [Table 3] shows harmonic types that explain own defense. 
[Table 3] Harmonic Type

\begin{tabular}{|c|c|c|}
\hline Classification & Type & Contents \\
\hline $\begin{array}{l}\text { The Positive Outlook } \\
\text { Group }\end{array}$ & $9,2,7$ & $\begin{array}{l}\text { They want to highlight and see the bright side of life. } \\
\text { I support positive moods so that others feel good too, because I am always in positive } \\
\text { emotions. }\end{array}$ \\
\hline $\begin{array}{l}\text { The Competency } \\
\text { Group }\end{array}$ & $3,1,5$ & $\begin{array}{l}\text { You learn to put your personal feelings behind you and deal with difficulties in an } \\
\text { objective and effective effort. }\end{array}$ \\
\hline The Reactive Group & $6,4,8$ & $\begin{array}{c}\text { respond emotionally to conflicts and problems, } \\
\text { It is difficult to know how much you trust others. } \\
\text { When problems arise, they respond emotionally and want to reflect their concerns. } \\
\text { Dislikes and likes are clear. }\end{array}$ \\
\hline
\end{tabular}

The Enneagram Head-Centered Type 7 is the type in which the ego ego escapes out of fear of the inner world. [Table 4] shows the positive aspects after examining the main contents of type 7.

[Table 4] Type 7 Features

\begin{tabular}{cc}
\hline Division & Main Content \\
\hline Emphasis & Emphasize positive experiences, enjoyable activities, excitement, and fun. \\
\hline $\begin{array}{cc}\text { Desire problem } \\
\begin{array}{c}\text { Avoidance } \\
\text { factor }\end{array}\end{array}$ & $\begin{array}{c}\text { Emphasize your own needs. } \\
\text { It is easy to feel that the needs of others are a burden. }\end{array}$ \\
\hline
\end{tabular}

There is no one who has purely one personality type of Enneagram wings. Everyone's aerograms are a mixture of their own base type and two adjacent types around the circle of the aerogram, where the type next to the base type is winged. Wings are basically secondary to the central type, so as a result, everyone has the characteristics of the central type and the characteristics of the wings at the same time. Wings are the second aspect of personality that should be considered for a deeper understanding of oneself. For example, if you are a personality type 9, you will have wings 8 and 1, and your personality will need to be determined by considering the characteristics of type 9 and type 8 and 1 . Also, everyone has important first wings and then second wings. The basic types are the same, but the nature of the basic types varies depending on the wings. For example, it differs markedly from type 2 with 3 wings and type 2 with 1 wing. The right balance emphasizes that the basic type of shortcomings should be avoided while saving the strengths of both wings.

\subsection{Prior Study on Enneagram}

Enneagram personality shows unique characteristics of each type interacting with each other, including emotional habits, characteristic mindset, and interpersonal relationships with others[23]. Therefore, Enneagram helps solve human problems and resolves interpersonal conflicts, which are applied to family counseling, counseling techniques, corporate management, and recruitment personnel, making it a useful tool for individual growth[23]. Nine personality types in the animation can bring understanding of others by exploring and understanding themselves, and knowing the personality types of themselves and others can create valuable insights. Therefore, it tells many important facts such as how others see the world, what decisions they are likely to make, what values they have, what are their main motivations for life, and how they react to people.

If you look at the preceding research on Enneagram and stress, you will see the following.

Stress is one of the most studied topics in many fields, including psychology, mental health, social 
science, and so on. In general, stress is a mental state in which a goal of value to oneself is threatened or lost, or when an environment is not necessary to achieve that goal. In other words, interpersonal factors generally refer to relationships with bosses, colleagues, and subordinate customers. Hackman and Oldham (1975)[24] emphasized the importance of interpersonal relationships, which can be represented by colleagues and bosses that members can form in the workplace, and played an important role in this interpersonal and motivation.

Modern times are very fast-changing and busy, and stress appears high. In particular, conflicts often discriminate, misunderstand, and reduce efficiency among groups in interpersonal relationships. In these areas, aniogram can help solve human interpersonal problems and reduce stress, making it a useful tool for personal growth[25]. In general, when stressed, the negative aspects of the characteristics of the Enneagram are particularly noticeable. When you are stressed out for a long time in your daily life, you habitually stray to the side. A positive attitude towards one's stress points can be said to provide insight into the life of thinking, feeling, and acting on one's own.

\subsection{Adjustment for Occupation}

Occupational adaptation is when an individual acts appropriately to match his or her needs with the requirements of the working environment. In other words, if an individual's work skills and environmental needs are harmoniously constructed, they have satisfaction, but if they are dissatisfied, the individual and the working environment attempt appropriate actions to match each other's requirements.

Occupational adaptation theory is a theory that describes individual satisfaction and environment satisfaction in their work-related behaviors and interactions with the environment. When both individuals and the environment remain satisfied, individuals can continue to maintain their jobs without moving from the organization and being fired. If occupational adaptation is regarded as a result of individual satisfaction and satisfying the needs of the organization, occupational maladjustment is related to the evaluation of individuals not getting enough satisfaction through the organization or the organization's performance. High job satisfaction not only increases the length of service, but also increases job involvement, fraud, overall life situation, non-work satisfaction, neglect behaviors such as job transition, absenteeism or lateness, and worker alienation. Furthermore, various characteristics of the current occupation fall short of one's expectations, others' assessment of one's occupation is low, and negative characteristics of the job, job stress, emotional instability, and discrepancy between individuals and occupations can lead to difficulties[26].

Super and Knassel (1981)[27] proposed career adaptation to adult career decisions. Career adaptation is a preparation for dealing with the ever-changing world of work and the needs of the Rephrase to surrounding environment. Career adaptation refers to psychological concepts for coping with changing work and job conditions, such as job development tasks, job transition, and career-related difficulties.

On the other hand, criticism has been raised for viewing the career selection process from a linear and rational perspective, including Super's, and constructivist career theory has emerged as an alternative theory, with the opinion that it is insufficient to explain career decisions in modern society. Career adaptation refers to psychological resources or personal abilities needed for a successful career transition, and empirical studies have also shown that career adaptation has a significant correlation with the reemployment status and reemployment quality of unemployed people[28]. The application of career adaptation will be an important factor in career-interrupted youth women's employment and career adaptation, given that young women employed after school age change their major roles to work. 


\section{Research Method}

\subsection{Research Subject}

The subject of the study is a 26-year-old client who is employed at $\mathrm{N}$ city. The family relationship is a single-parent family, living with their paternal grandparents, and grandfather died of illness 10 years ago, and now living with her grandmother, father, younger brother and younger sister. The main appeal of the client is that she is stressed because is not good at expressing difficulty in interpersonal relationships.

This study was conducted once a week, 60 minutes a week, in 20 sessions including pre- anob stress from December 7, 2020 to April 26, 2021. This study analyzed the post-mortem sessions of a young woman complaining of interpersonal relationship and job stress. Through a case study, the factors contributing to stress on interpersonal relationship and job were identified.The research participant complained of psychological difficulties, expressing negative emotions such as depression, lethargy, and anger at the time of the request, and talked about interpersonal problems and difficulties in daily life.

As a single case study, a mixed study was conducted combining quantitative and qualitative studies of psychological tests.

\subsection{Research Tools}

\subsubsection{Interpersonal Measuring Tools}

To measure interpersonal ability, the Interpersonal Competence Questionnaire (ICQ) used a translation of Kim Chang-dae and Kim Soo-im (1999)[29]. The scale consists of a total of 40 questions and uses a Likert 5-point scale, and the higher the total score, the more adaptive the interpersonal ability is. For each question, they can be answered with Both one and two are interpreted as not at all" three "ordinary," four "yes" and five "very yes," and six questions on the questionnaire are reverse scoring questions. The interpersonal capacity measure consists of five subdimensions: first-time relationships, claims of rights, self-exposure, emotional support, and interpersonal conflict. Cronbach's a for first-time relationship is.78, rights claims .82, self-exposure .65, emotional support .79, and interpersonal conflict handling .69.

\subsubsection{Job Stress}

This study used a Korean-style job stress measurement tool (KOSS) developed by Jang Se-jin et al. (2005)[30] to measure job stress of office workers, and is a standardized measurement tool that has undergone accuracy and reliability evaluation research. The questionnaire consists of five sub-factors: job-related, interpersonal, organizational, compensatory and workplace culture, measured on a Likert 4point scale. For each question, they can be answered with 1 point for one and two are interpreted as not at all. 3 points for 'Yes', and 4 points for 'Very Yes', and 3, 5, 6, 7, 8, 9, 10, 11, 12, 14, 15, 16, 17, and 18 are reverse scoring questions. The result means that the higher the response score, the higher the level of job stress. The internal agreement of the question is .801 .

\subsection{Ethical Consideration of Research Participants}

This study contacted participants who expressed their intention to participate in the study individually to explain the purpose of the study and the course of counseling on occupational adaptation and to obtain consent. The research process was described once in advance, including the purpose and method of the study, the status or anonymity of the research participant, the type and method of data collection, the 
right of the participant to voluntarily stop participating, and the researcher and research participant's signature.

\section{Meaning of Experience}

This study allows young women to understand themselves through the process of talking about how they view and accept themselves after employment, and how they lead and accept themselves in certain directions. It was also provided as an important material to deeply empathize and understand the lives of young adult job seekers through repeated listening and reading processes.

\subsection{Understanding Ownself}

Individuals live in their own experiences. Through this world of experiences, the inner value system is formed. The world of this experience is positive and has received a lot of love and support, and the conditioning of value formed when it is not. That is, depending on the parent's parenting style and attitude, the terms of value also differ[31]. Also, the core of the social expectation model is that children not only feel incompetent because they do not meet their parents' expectations, but also experience helplessness and despair.

Session 1: The subject's grandmother had a cerebral infarction in August last year, so she stayed in the hospital to take care of her grandparents, which was opposed by her aunt, mother and uncle. One time, her grandmother went to the day care center and came home in the evening because of health improvement. In the evening, she pinched her and said that she could not sleep.

Session 2: Her junior said he had no place to go and so spent two months with her. However, the junior was stressful because he has no sincerity to help with housework and looked lazy when asked to do it. Her friend also said told her that the junior have been with her for two months. He was helped voluntarily by the subject without telling anyone.

Session 3: The subject said that she was cautious when she meets new people. In the previous year, she said that she could not socialize. We asked her on what part. She said that the argument makes the situation awkward and she does not like it. She said it would be better to see it maturely.

Session 4: Yesterday, she gave food to her grandmother. However, she did not eat it and pinched her all day. When her grandmother had a cerebral infarction, she only looked for her. If her grandmother's dementia gets worse, she will send her to a nursing home. Her mother had never take care of her grandmother. We believe its best not to tell us that she is tired.

Session 5: While living with her grandmother and grandfather, he found his grandfather to be a scary man. He told her to sleep at 8:30 p.m. and wake up at 5 a.m., and to eat the food that her grandmother prepared. When she was bullied in middle school, she did not tell about the bully and her family may still not know.

Session 6: The subject's brother ran away from home for four days in high school. Even now, when they argue about wealth, grandmother, and cousins, his brother said that their father took charge of it, but, it was the subject that did it. She said she felt more difficult dealing with relationships than in-house work. It was difficult to make her act differently and lie.

\subsection{Stories of Everyday Experiences}

Min-jung (pseudonym) thought she was good at work by quickly acquiring various fields at work. But, when she was told by an acquaintance that she was not good at social life, she refuted it, instead experienced frustration because she was not accepted. Given these difficulties and poor relationships between wealth and her grandmother's situation, despite the need for a difficult and hurtful 
psychological recovery in interpersonal relationships, her experience of rejection and her grandmother's situation made her passive.

Min-jung (pseudonym) is Enneagram No. 7, which covers what is new and different from the outside, and believes that everything will eventually be done if it is thought right enough. We have created a habit of suppressing the feelings that are currently hiding behind the civil government (pseudonym) and thinking and talking about what they wanted to do to resolve those feelings. It is very careful and difficult to express one's pain to others. However, she used the media as an opportunity to reflect on what she had to shake off and overcome by expressing suppressed psychological pain such as workplace stress and irritation and anger in interpersonal relationships.

Session 7: The subject expressed her current state in a sand box, as a volcano that was about to burst. She said she hoped the volcano would stop boiling. When she expressed the volcanic eruption, she knocked down trees and animals and said that only tigers lived there. Through this, we hope that those who made it difficult for her would know even a little bit about their mistakes.

Session 8: The subject said she was friendly with her family. Her brother had a lot of things going on in high school and was involved in fraud, and so their father had to solve it. She told her brother that she did not want to see him wearing luxury goods in a foreign car. She said she had a hard time seeing her father get stressed out because of his brother.

Session 9: One card was drawn from the inner active card, and the positive sided card was the moon and the earth. They became one and lived in a different world because the negative side and reality were different. She said that she was excited when she has nothing to do. She was excited when she played with her friends until her sixth year in elementary school. She lost contact with her friends who went to Iljin in middle and high school.

\subsection{Informing Your Strengths}

Min-jung's grandmother had been hospitalized since last year due to severe dementia after a cerebral infarction, and she only visited Min-jung frequently and hired a caregiver. She said that she took her grandmother home because her health improved a lot and saw her living at a day care center during the day and at home in the evening, and that her aunt complimented her for taking good care of her. Overcoming the difficulties of interpersonal relations, she recognized that her self-esteem increased while serving as a department representative and chairman of the association. Seligman (2002) said that happiness is the way for individuals to lead a pleasant life, engaged life, and meaningful life by realizing and developing their positive characteristics and strengths and utilizing them in the field of daily life. Looking at Min-jung (pseudonym) trying to form a positive self-image, we were also able to feel the joy of being a guide along the journey of Min-jung (pseudonym) and became an opportunity for growth.

Session 10: The subject said that her parents seemed to have an intimate relationship with her grandmother after her grandmother got sick. Before, her parents did not take care of her grandmother and only relied on the caretaker, but now they would take care of her. Her parents' brothers said that they had no one to take care of her grandmother except for their father, so the subject felt like the grandmother's guardian, but it was okay.

Session 11: When asked who caused the problem in the family and who seemed to solve them, the subject's parents cannot answer because they do not know who. Her grandmother said that she had dementia since last year. Her aunt is the one who complimented her because her grandmother's situation improved. However, the subject felt awkward about it.

Session 12: The subject learned to consult others in high school. When she consulted her teacher for career counseling, the teacher said "You can't enter with your grades.". Her teacher said she wanted her to study harder. She has been in touch with the teacher who supported and encouraged her during her second year in high school. In addition, she said that her self-esteem increased when she became the 
department representative and president of the association.

\subsection{Social Support System}

Social support refers to what can be gained from important interpersonal relationships, friends, neighbors, parents and siblings, close relatives, and all other positive resources from social life (sim Eung-cheol, comradeship, pig kyu, 2008). No.7 type of enthusiasm, macrophage, keeps you moving from job to job from relationship. Travel is a very important part of their world because it continues to provide new experiences. Min-jung (pseudonym) had the same job evaluation and administrative stress at work, care for grandmothers and dogs at home, and interpersonal difficulties. However. she had the opportunity to gain gratitude and strength from her immediate boss who supported her and helped her complete her work.

Session 13: The subject said she is stressed out because she does not want to work, nor go to work, nor write a diary and administer it. She likes working but not office work. But she had to earn money. When asked what causes her stress, she said that her grandmother, dog, and work could actually be stressful.

Session 14: She drew a picture of herself in the rain, in a boat on the river where she is lying in. The rain is pouring heavily. When asked what would happen if it kept raining, she said she would catch a cold and be sick. She explained that if it rains heavy, the boat can be submerged and that stress management and self-care are needed.

Session 15: The subject said that starting this year, the CEO came once a week before the evaluation, which stresses her when he looked at the accounting. Not until last year, when evaluating documents, the director of the center helped her lessened her stress with an accounting done once a month. She planned to take a day off before then because she had been evaluated since May.

Session 16: The job of a physician requires a lot of work at the same time, creativity, and is given the authority to make decisions during work hours and during work performance, and was able to exert influence. She said that her immediate boss helped her complete her work and recognized and understood her when she was having a hard time. Now, she is expressing her anger by watching good things and relieving her stress with good videos and driving.

\subsection{Designing Future Lives}

It was so hard and difficult for Min-jung to face herself that felt like pain. However, she looked back on herself through media activities and recognized her efforts and experiences. She also realized that there were supporters around her including her immediate superior who believed and supported her silently. The subject experienced changes that strengthen her self-overcoming self-awareness by expressing various psychological and emotional conflicts in the inner world as a visualization result through artistic activities.

Session 17: Her grandmother had a recurrence of cerebral infarction but the hospital told her to look for rehabilitation facilities and nursing homes. She was worried about sending patients to rehabilitation facilities. She felt like she could take care of her grandmother and if she was sent to rehabilitation facilities, she needs to be careful constantly.

Session 18: She said it was fun and pleasant to get to know new people. She could claim her rights when people ignore her or treat her as a trifle. Also, they said that they can refrain her opinion which may cause heavy arguments due to differences in opinions. It is difficult even for close people to express their affection. 


\subsection{Acceptance and Future Planning}

Humans look back on their past and imagine the future to come, living a life in which they continuously create physical time given in the present progressive form of a single semantic system with beginnings, developments, and endings[32]. A type 7 realizes that he is free and originally free when he is willing to escape from the phenomenon, i.e. giving up finding happiness in a phenomenal experience. Min-jung (pseudonym) looked back on her path from the past to the present, understood and accepted her reality, and got an opportunity to move her life in a more meaningful direction.

Session 19: After her grandmother's death, she felt a lot of emptiness and she couldn't sleep for a few days. She was angry and annoyed when her mother told her brother that she struggled to live with her grandmother because she felt that she was an enemy or thorn. She also told her not to go around late at night.

Session 20: The subject said she started off on the spot when she was curious about something, but quickly gave up when it was not funny. When she visited the funeral, many guests from various fields came. She said she enjoyed meeting a variety of people and the network was extensive.

\section{The Result of the Study}

\subsection{Interpersonal Pre-Post-Effect}

[Table 5] Interpersonal Pre-Post-Personal Examination

\begin{tabular}{c|c|c}
\hline Subfactors & Before & After \\
\hline \hline First time for relationship & 25 & 31 \\
\hline Claims of Rights & 19 & 26 \\
\hline Self-exposure & 15 & 21 \\
\hline emotional support & 21 & 32 \\
\hline support with interpersonal conflict & 24 & 30 \\
\hline Average & 20.80 & 28.00 \\
\hline
\end{tabular}

As shown in [Table 5], the results of interpersonal testing showed changes from 20.80 point average to 28.00 post average across interpersonal relationships. Looking at each sub-region, first time relationship increased from 25 points to 31 points, the rights claim from 19 points to 26 points, selfexposure from 15 points to 21 points, emotional support from 21 points to 32 points, and support in interpersonal conflict from 24 points to 30 points. This showed improved results in all scores of interpersonal subfactor domains appealed by the study participant. It can be predicted that this change is finding a sense of interpersonal psychological stability by indicating changes in the participant's human relationship, although there is no change shown.

As shown in [Table 6], the results of the job stress test showed a change from 16.20 points average for the entire job stress to 11.80points, the post average. Looking at each sub-region, the job-related matter decreased from 23 points to 18 points, for interpersonal relationships from 10 points to 3 points, in organizational relation from 11 points to 8 points, the reward scheme from 19 points to 14 points, and workplace culture from 18 points to 16 points. These changes appeared after her grandmother's death. This showed improved results in all scores of job stress-related subfactors that the study participant appealed to. These changes do not involve job-related changes for participant, but we can predict that she is gradually controlling job stress through counseling. 
[Table 6] Job Stress Pre-Post Effect

\begin{tabular}{c|c|c}
\hline Subfactors & Before & After \\
\hline \hline Job-related & 23 & 18 \\
\hline Interpersonal relationship & 10 & 3 \\
\hline Organization-related & 11 & 14 \\
\hline Compensation system & 19 & 16 \\
\hline Work culture & 18 & 11.80 \\
\hline Average & 16.20 &
\end{tabular}

\section{Conclusion}

The goal of the consultation was to enable the subject to express negative feelings from job stress and to relieve psychological difficulties resulting from stress response patterns and to help discover selfgrowth and hope for the future.

The participant was able to understand herself, told stories of daily experiences, her strengths, and social support systems, and designed her future to provide daily vitality and joy, and an opportunity to find new life directions by looking at work opportunities separately from job stress. Based on the results of this study, the conclusions on experience and meaning are as follows.

First, the participant was able to recognize and reflect on herself by knowing the type of Enneagram personality, understanding and expressing herself during the consultation process by re-enacting their daily vitality and imaging the current state. The study provided opportunities to design one's future positively by separating oneself from job stress.

Second, through counseling, the research participant was effective in dealing with first-time relationships, claims of rights, self-exposure, emotional support, interpersonal conflict, job stress, and job-related, interpersonal, organizational, compensation, and workplace culture.

This study is a single case study that recognizes the meaning of experience, which can be centered on experience and its meaning. First, employment is not just the meaning of a job, but the process of recognizing social relationships and finding oneself. Having a job means successfully performing one's role, achieving economic independence and self-realization as well as psychological stability, and will require a love for jobs. Therefore, it is necessary to fully reflect on one's aptitude, interest, and desire. In the counseling scene, the therapeutic relationship between the caller and the counselor is essential to self-exposure, and as it promotes intimacy in general relationships, it can contribute to the development of the counseling relationship through likes and responses to the counselor.

These experiences provided daily vitality and pleasure and provided insight into self-inspiration and current life by looking at oneself separately from job stress. This study is intended to help young women preparing to adapt to their jobs after employment find themselves.

The limitations of this study are as follows. Although it is difficult to generalize it as a single case, it is meaningful that it was developed focusing on cases in which counseling was conducted according to the types of participants by classifying them.

Therefore, the support system of the the subject and her family suggests empathy, consideration, trust, and interest, and that psychological high emotional support and daily life he or she experiences are effective in decreasing stress related to interpersonal relationships and job.

This study investigated the Enneagram type and conducted counseling according to the type. It is very 
useful for understanding the client's detailed information.

\section{Reference}

[1] G. J. Kwak, Shaking 20s: Adolescent Life Planning Psychology, Seoul National University Press and Cultural Center, (2010)

[2] www.koreaherald.com, Jun 22 (2021)

[3] S. Y. Kim, S. K. Kang, The Predictors of Sheltered Workshop Program Utilization of Individuals with Mental Illness in the Long-term Care Mental Institutions : Focusing on the mental illness stigma of mental health professionals, Mental Health \& Social Work, (2018), Vol.46, No.3, pp.34-63, DOI: 10.24301/MHSW.2018.06.46.3.34

[4] B. H. Lee, K. J. Hong, S. E. Lee, B. K. Kang, J. Y. Yoon, Poverty Poverty Act and Support Policies, Korea Labor Institute, (2010)

[5] https://kostat.go.kr, Jun 22 (2020)

[6] Mental health business guide, Ministry of Health and Welfare, (2020)

[7] S. J. Jang, (A) Relationship Psychological Growth Environment, Resilience of Adjustment and Characteristics of Juvenile Delinquency Tendencies, Wonkwang University, Master's thesis, (2003)

[8] K. H. Lee, B. H. Kim, Interpersonal Ability: Comparison of Clusters by Emotional Clarity, Affect Intensity, and Emotion Regulation Style, Korean Journal Of Counseling And Psychotherapy, (2010), Vol.22, No.2, pp.369-384, UCI: G704000523.2010.22.2.011

[9] K. S. Jo, B. Kim, The Mediating Effect of Stress Coping Methods on the Relationship Between Achievement Goal Orientation and the Academic Procrastination Among the Chinese Students in South Korea, Journal of Social Science, (2017), Vol.43, No.2, pp.239-262, DOI: 10.15820/khjss.2017.43.2.010

[10] S. W. Song, S. J. Jang, J. H. Lee, M. A. Min, The Relationship Among Job Stress, Teacher Efficacy, Ego Resilience, and Burnout of the Elementary School Teachers, Korean Journal of Teacher Education, (2010), Vol.26, No.4, pp.1737, UCI: G704-002088.2010.26.4.011

[11] R. S. Lazarus, The Stress and Coping Paradigm, Models for Clinical Psychopathology, Spectrum, pp.177-214, (1981)

[12] R. S. Lazarus, S. Folkman, Stress, appraisal and coping, Springer Publishing Company, (1984)

[13] J. C. Park, J. S. Kim, The Effects of Entrepreneurial Self-efficacy on Entrepreneurship of University Students: Moderating Effects of Entrepreneurial Education and Career Uncertainty, Asia-Pacific Journal of Business Venturing and Entrepreneurship, (2019), Vol.14, No.3, pp.27-38, DOI: 10.16972/apjbve.14.3.201906.27

[14] M. J. Shim, G. N. Seo, The Effects of Group Play Therapy on the Social Skills of Children with Intellectual Disabilities, The Journal of Play Therapy, (2019), Vol.25, No.1, pp.45-57.

[15] N. S. Endler, J. D. A. Parker, Stress and anxiety: Conceptual and assessment issues, Stress Medicine, (1990), Vol.6, No.3, pp.243-248, DOI: https://doi.org/10.1002/smi.2460060310

[16] S. A. Kim, A Study for Practical Establishment of the Adolescent Welfare: Focusing on a Developmental Welfare Approach for the Adolescent compare to the Child Welfare Practice, Youth Welfare Research, (2010), Vol.12, No.4, pp.279-299, UCI: G704-002137.2010.12.4.008

[17] H. K. Heo, I. S. Park, Influence of Childcare Teachers' Quality and Work Attitude on Childcare Quality, The Korea Association of Child Care and Education, (2010), No.64, pp.21-41, UCI: G704-000724.2010..64.002

[18] J. J. Arnett, Emerging adulthood: The winding road from the late teens through the twenties, Oxford University Press, (2007)

[19] H. S. Jang, The Relationship of Developmental Tasks and Happiness in Early Adulthood, The Korean Journal of Developmental Psychology, (2009), Vol.22, No.1, pp.19-36, UCI: G704-000281.2009.22.1.007 
[20] K. H. Kim, G. Y. Jang, G. S. Jo, A Study on the Development of Youth Core Competencies and Implementation Plan III: General Report, National Youth Policy Institute, pp.1-232, (2010)

[21] J. Y. Kim, Effects of elderly at creative dancing program on depression and stress, Resach of Dance Education, (2009), Vol.20, No.3, pp.119-133, UCI: G704-001060.2009.20.3.008

[22] S. H. Lee, Invitation to the Vision Enneagram, Vision Enneagram Education Institute, (2009)

[23] Y. S. Yoon, Enieagram Personality type scale, Korean Journal of Educational Psychology, (2001), Vol.15, No.3, pp.131-161.

[24] J. R. Hackman, G. R. Oldham, Development of the job diagnostic survey, Journal of Applied Psychology, (1975), Vol.60, No.2, pp.159-170, DOI: 10.1037/H0076546

[25] E. J. Kim, Development and Validation of Adolescent Enneagram Personality Type Scale, Sookmyung Women's University, Ph.D dissertation, (2008)

[26] B. A. Fritzsche, T. J. Parrish, Theories and research on job satisfaction, Career development and counseling: Putting theory and research to work, John Wiley\&Sons, pp.180-202, (2005)

[27] D. E. Super, E. G. Knasel, Career development in adulthood: Some theoretical problems and a possible solution, British Journal of Guidance \& Counseling, (1981), Vol.9, No.2, pp.194-201, DOI: 10.1080/03069888108258214

[28] E. A. Gallie, S. McArdle, B. Rivard, H. Francis, Estimating sulphide ore grade in broken rock using visible infrared hyperspectral reflectance spectra, International journal of remote sensing, (2002), Vol.23, No.11, pp.2229-2246, DOI: $10.1080 / 01431160110075604$

[29] C. D. Kim, S. I. Kim, A study on the effect of a group counseling program to improve interpersonal skills, student research, (1999), Vol.35, No.1, pp.83-95.

[30] Sei Jin Chang, Sang Baek Koh, Dongmug Kang, Seong Ah Kim, Myung Geun Kang, Chul Gab Lee, Jin Joo Chung, Jung Jin Cho, Mia Son, Chang Ho Chae, Jung Won Kim, Jung Il Kim, Hyeong Su Kim, Sang Chul Roh, Jae Beom Park, Jong Min Woo, Soo Young Kim, Jeong Youn Kim, Mina Ha, Jungsun Park, Kyung Yong Rhee, Hyoung Ryoul Kim, Jeong Ok Kong, In Ah Kim, Jeong Soo Kim, Jun Ho Park, Sook Jung Huyun, Dong Kook Son, Developing an Occupational Stress Scale for Korean Employees, Annals of Occupational and Environmental Medicine, (2005), Vol.17, No.4, pp.297-317, DOI: 10.35371/kjoem.2005.17.4.297

[31] H. M. Park, M. L. Ahn, Study on the Development of a Free Learning Semester Program for the Cultivation of Global Citizenship of the Youth, The Journal of Learner-Centered Curriculum and Instruction, (2015), Vol.15, No.6, pp.217247, UCI: G704-001586.2015.15.6.026

[32] S. J. Lee, S. S. Park, Educational Psychology, Korea Open University Publishing \& Cultural Center, (1999) 